\title{
The development of a nomogram to predict post-radiation necrosis in nasopharyngeal carcinoma patients: a large-scale cohort study
}

This article was published in the following Dove Press journal: Cancer Management and Research

\author{
Xiao-Yun $\mathrm{Li}^{1,2, *}$ \\ Xue-Song Sun ${ }^{1,2, *}$ \\ Sai-Lan Liu ${ }^{1,2, *}$ \\ Qiu-Yan Chen ${ }^{1,2}$ \\ Shan-Shan Guo ${ }^{1,2}$ \\ Li-Ting Liu ${ }^{1,2}$ \\ Jin-Jie Yan $^{1,2}$ \\ Hao-Jun Xie ${ }^{1,2}$ \\ Qing-Nan Tang ${ }^{1,2}$ \\ Yu-Jing Liang ${ }^{1,2}$ \\ Ling Guo ${ }^{1,2}$ \\ Lin-Quan Tang ${ }^{1,2, *}$ \\ Hai-Qiang Mai ${ }^{1,2, *}$
}

\begin{abstract}
'State Key Laboratory of Oncology in South China, Collaborative Innovation Center for Cancer Medicine, Guangdong Key Laboratory of Nasopharyngeal Carcinoma Diagnosis and Therapy, Sun Yat-sen University Cancer Center, Guangzhou 510060, People's Republic of China; ${ }^{2}$ Department of Nasopharyngeal Carcinoma, Sun Yat-sen University Cancer Center, Guangzhou 510060 , People's Republic of China
\end{abstract}

*These authors contributed equally to this work

\begin{abstract}
Objective: This study aimed to establish a nomogram to predict the risk of post-radiation necrosis in nasopharyngeal carcinoma (NPC) patients.

Background: This study was performed to identify influencing factors for developing postradiation necrosis, and to establish an effective nomogram model to predict individual risks in NPC patients.
\end{abstract}

Methods: 7144 NPC patients receiving radical radiotherapy from 2007 to 2012 were involved in the study, and 207 of them developed nasopharyngeal necrosis (NPN). The clinical characteristics and baseline laboratory results were collected and analyzed. Independent predictive factors were selected using the Cox proportional model and incorporated into the nomogram. The receiver operating characteristic curve and the calibration curve were used to verify discrimination and calibration.

Results: The experience of re-irradiation contributed most to the occurrence of NPN (HR, $15.56,95 \%$ CI $10.84-22.35, p<0.001)$. Clinical factors including age, pathology type, history of diabetes, and original T stage were independent predictors of NPN. Factors reflecting patients' baseline nutritional and inflammatory status such as hemoglobin, albumin, and C-reactive protein were also significantly associated with the development of NPN. With all independent predictive factors incorporated, a nomogram was generated, and it showed excellent discrimination and calibration.

Conclusion: This study was the first large-scale cohort study focusing on the development of NPN and established a nomogram to predict its occurrence based on the clinical and laboratory indicators. The nomogram demonstrated good discriminative capacity and satisfactory agreement, which would offer valuable clues for clinicians to distinguish the highrisk NPN population and maintain close surveillance.

Keywords: nasopharyngeal carcinoma, necrosis, radiotherapy, adverse effect

\section{Introduction}

Nasopharyngeal carcinoma (NPC) is a malignant head and neck cancer with an unbalanced global distribution. The peak incidence in endemic regions including southern China and Southeast Asia reaches 50 cases per $100,000 .{ }^{1}$ Radiotherapy is the mainstay treatment for NPC. Despite the extraordinary local control rates brought by radiotherapy, this treatment may cause both acute and chronic adverse effects to the soft tissues and bones surrounding the nasopharynx. As more irradiated NPC patients survive after treatment, the presence of various post-radiation complications should raise more concerns. $^{2}$

\footnotetext{
Correspondence: Hai-Qiang Mai; Lin-Quan Tang

Department of Nasopharyngeal Carcinoma, Sun Yat-sen University Cancer Center, 65I Dongfeng Road East, Guangzhou 510060, People's Republic of China

Tel +86 $2087343380 ;+862087343155$ Fax +86 208734 3392; +86 2087343392 Email maihq@sysucc.org.cn; tanglq@sysucc.org.cn
} 
Post-radiation nasopharyngeal necrosis (PRNN) is a devastating adverse effect of radiotherapy for NPC. ${ }^{3}$ Patients with PRNN usually present with severe headache, foul odor, and epistaxis, which seriously compromise patients' quality of life. ${ }^{3,4}$ Severe and even fatal consequences of PRNN, including massive hemorrhage, intracranial infection, and cachexia, have occasionally been seen, ${ }^{3,4}$ especially when the carotid sheath is involved and the carotid artery is eroded. ${ }^{3}$ Published literature for PRNN is quite limited, and the survival outcomes of these patients are generally poor, with Yang et $\mathrm{al}^{5}$ reporting 1-year and 2-year overall survival (OS) rates of $65.0 \%$ and $51.6 \%$, respectively. ${ }^{5}$ Therefore, it is essential to facilitate early identification of NPC patients with a higher tendency for PRNN and implement effective interventions to prevent the occurrence of as well as reverse the deterioration of PRNN.

In recent years, with an improved understanding of PRNN, emerging studies focused on finding the risk factors leading to PRNN. ${ }^{3,4,6-9}$ The accumulated dosage of radiation is generally recognized as an important risk factor for the severity of necrosis. ${ }^{3,4-6-8} \mathrm{Yu}$ et al's study ${ }^{9}$ established a model that includes sex, pretreatment necrosis, accumulated total prescription dose to GTV, and recurrent tumor volume to predict the risk of nasopharyngeal necrosis (NPN) in NPC patients who receive re-irradiation. ${ }^{9}$ In addition to their findings, we also found a strong correlation between the development of PRNN and some inflammatory and nutritional factors in our clinical practice. To better understand the predictive potential of these factors and make a thorough analysis of the pathophysiology of PRNN, a nomogram is developed to estimate the individual risk of PRNN. The nomogram is a reliable statistical predictive model, which is simple and explicit, and can accurately present the risk of PRNN. We hope this nomogram could serve as a valuable decision-making tool for clinicians to take precautions against PRNN.

\section{Methods}

\section{Patients}

From January 2007 to December 2012, we retrospectively reviewed the clinical data of 7144 stage I-IVb NPC patients treated consecutively at Sun Yat-sen University Cancer Center (SYSUCC). The inclusive criteria of this study were as follows: 1) histopathologically confirmed NPC; 2) age $\geq 18$ years; 3 ) received radical radiotherapy treatment; 4) radiologically measurable disease; 5) Karnofsky performance score $>60 ; 6$ ) absence of pregnancy, lactation, and other malignant disease; and 7) normal renal and liver function. All patients were evaluated by complete physical examination, head and neck computed tomography (CT) or magnetic resonance imaging (MRI), chest radiograph, abdominal sonography, electrocardiography, nasopharyngoscopy, bone scan or positron emission tomography-computed tomography (PET-CT), and laboratory tests including blood routine and biochemical profiles. Patient information such as sex, age, family history of NPC, smoking status, and history of cardiovascular disease and diabetes mellitus was also collected besides the pretreatment evaluations. All patients were staged based on the seventh TNM staging manual from the American Joint Committee on Cancer. ${ }^{10}$ This research was conducted in accordance with the Declaration of Helsinki. The Clinical Research Ethics Committee of the SYSUCC approved this study and each participant provided written informed consent prior to treatment.

\section{Diagnosis and treatment of PRNN}

The diagnosis of PRNN was made according to the symptoms of and results from nasopharyngoscopy or MRI. Symptoms like a foul nasal smell, refractory headache, and thick necrotic secretions were strong indicators of PRNN. Nasopharyngoscopy revealed necrotic lesions and sometimes exposed bone covered by secretions in the nasopharyngeal cavity. MRI images often showed a discontinuous nasopharyngeal mucosa line and/or nonenhanced tissue defects. After PRNN was detected, endoscopic debridement and excision every 2 weeks and daily nasopharyngeal irrigation with $2 \%$ aquae hydrogen dioxide or saline were given. Endoscopic necrectomy was performed when no contraindications were observed. Systemic antibiotics and intravenous nutrition support were provided if necessary.

\section{Follow-up and outcomes}

OS was defined from the first day of diagnosis of NPC to the day of death from any reasons. In the first 3 years, all patients received reexamination every 3 months, and then every 6 months until death. A complete physical examination was performed at each visit. Besides, nasopharyngoscopy, contrast-enhanced MRI of the nasopharynx and neck, ultrasound/enhanced CT scan of the abdomen, and radiography/enhanced $\mathrm{CT}$ scan of the chest were done routinely. PET-CT was considered if necessary. 


\section{Statistical analysis}

Categorical variables were classified based on clinical findings, and continuous variables were transformed into categorical variables based on routine cutoff points in clinical application. The standard chi-square test was used for comparative analysis. The associations between NPC patients' clinical characteristics and the risk of PRNN were evaluated using univariate logistic regression analysis. Significant variables with $p<0.05$ were entered into the multivariate logistic analysis to identify the independent risk factors for PRNN. On the basis of results from the multivariable analysis, a nomogram for PRNN probability was constructed using a backward step-down process, and model fitting was evaluated using the Akaike information criterion. The Hosmer-Lemeshow test was used to assess the fit of the regression model. The discriminative performance of the nomogram was assessed by receiver operating characteristic (ROC) curve, and the calibration was assessed by the calibration curve.

The survival curve was estimated using the KaplanMeier method, and comparisons of the survival rate between or among patients with different characteristics were assessed by the log-rank test. ${ }^{11}$ All statistical analyses were carried out with SPSS version 21.0 (IBM Corporation, Armonk, NY, USA) or with R 3.5.1 (The R Foundation for Statistical Computing, Vienna, Austria). For all analyses, a result of $p<0.05$ was considered statistically significant.

\section{Results}

\section{Clinical characteristics and failure}

\section{patterns}

From January 2007 to December 2012, data on a consecutive series of 7144 NPC patients (5279 male and 1865 female) treated at SYSUCC were analyzed. The median age was 46 years (IQR, 39-55 years). After the median interval of 12.4 months from the end of treatment to the detection of NPN, a total of 206 patients had developed NPN, yielding an incidence rate of $2.9 \%$. Details of the cohort are shown in Table 1.

Among the NPN population, 57 (27.7\%) developed the condition after receiving re-irradiation. The median followup was 56.8 months. The estimated 5-year OS rate for NPN patients was $63.8 \%$, which was much lower when compared with the control cohort $(63.8 \%, 95 \%$ CI $56.5-71.0 \%$ vs $85.6 \%, 95 \%$ CI $84.6-86.6 \%, p<0.001$ ) (Figure 1). Overall, $115(55.6 \%)$ NPN patients died: $61(53.0 \%)$ deaths were caused by radiation or necrosis-related adverse events including hemorrhage and intracranial infection, etc., 22 (19.1\%) cases were locoregional relapse-related, while 23 $(20.0 \%)$ were due to distant metastasis.

\section{Factors associated with NPN}

All potential influencing factors associated with NPN from clinical characteristics to laboratory indexes were analyzed in our study. The results of the univariable and multivariable analysis are summarized in Table 2. Among demographic and clinical factors, older age ( $>45$ years $)(p=0.008)$, existing status of diabetes $(p=0.001)$, and pathological type of WHO I-II NPC $(p<0.001)$ were found to correlate with a higher incidence of NPN. The more advanced initial stage of both primary tumor $(p=0.003)$ and nodal status $(p=0.020)$ were also factors that had an impact on NPN. In terms of radiotherapy, patients receiving intensitymodulated radiotherapy or re-irradiation were more likely to develop NPN. Pretreatment laboratory results, which reflected the baseline nutritional and inflammatory status, were also collected and analyzed. Inferior levels of hemoglobin (HGB), albumin (ALB), and C-reactive protein (CRP) were all strong prognosticators for the occurrence of NPN. All significant factors in the univariable analysis were considered to enter into the multivariable analysis.

\section{The establishment of the nomogram model for NPN prediction}

The final nomogram model was established after the model fitting procedure using the Akaike information criterion (Figure 2). It showed that re-irradiation was the dominant factor for the nomogram model, followed by HGB level $<110 \mathrm{~g} / \mathrm{L}$, ALB level $<35 \mathrm{~g} / \mathrm{L}$, and a status of diabetes. Other factors showed moderate impacts on the NPN prediction. The different status of each factor corresponds to a specific score on the point scale, and a total score could be calculated for individuals with all factors considered. By locating it on the total point scale, it is easy to predict the estimated probability of NPN incidence.

\section{The discrimination and calibration ability of the nomogram}

The ROC curve was used to evaluate the discrimination of this model according to the predictive value in the logistic analysis (Figure 3). The nomogram demonstrated good discrimination ability for predicting NPN with an area under the ROC curve of 0.78 (95\% CI, 0.75-0.82). The model was well calibrated according to the Hosmer-Lemeshow test 
Table I Patient characteristics of the cohort

\begin{tabular}{|c|c|c|c|c|}
\hline \multirow[t]{2}{*}{ Characteristic } & \multicolumn{4}{|l|}{ Number of patients (\%) } \\
\hline & Total cohort $(n=7 \mid 44)$ & Control cohort $(n=6938)$ & Necrotic cohort $(n=206)$ & $p$ \\
\hline $\begin{array}{l}\text { Age (years) } \\
\quad \begin{array}{l}18-45 \\
\geq 46\end{array}\end{array}$ & $\begin{array}{l}3566(49.9) \\
3578(50.1)\end{array}$ & $\begin{array}{l}3482(50.2) \\
3456(49.8)\end{array}$ & $\begin{array}{l}84(40.8) \\
122(59.2)\end{array}$ & 0.009 \\
\hline $\begin{array}{l}\text { Gender } \\
\text { Female } \\
\text { Male }\end{array}$ & $\begin{array}{l}1865(26.1) \\
5279(73.9)\end{array}$ & $\begin{array}{l}182226.3) \\
5116(73.7)\end{array}$ & $\begin{array}{l}43(20.9) \\
163(79.1)\end{array}$ & 0.091 \\
\hline $\begin{array}{l}\text { BMI } \\
\quad<18.5 \\
18.5-22.9 \\
23.0-27.9 \\
\geq 28\end{array}$ & $\begin{array}{l}603(8.4) \\
3208(44.9) \\
2922(40.9) \\
411(5.8)\end{array}$ & $\begin{array}{l}587(8.5) \\
3110(44.8) \\
2838(40.9) \\
403(5.8)\end{array}$ & $\begin{array}{l}16(7.8) \\
98(47.6) \\
84(40.8) \\
8(3.9)\end{array}$ & 0.626 \\
\hline $\begin{array}{l}\text { EBV DNA level } \\
\begin{array}{l}<1000 \\
1000-9999 \\
10,000-99,999 \\
\geq 100,000\end{array}\end{array}$ & $\begin{array}{l}2834(39.7) \\
|87|(26.2) \\
1466(20.5) \\
973(13.6)\end{array}$ & $\begin{array}{l}2756(39.7) \\
1815(26.2) \\
1413(20.4) \\
954(13.8)\end{array}$ & $\begin{array}{l}78(37.9) \\
56(27.2) \\
53(25.7) \\
19(9.2)\end{array}$ & 0.108 \\
\hline $\begin{array}{l}\text { Pathology type } \\
\text { WHO III } \\
\text { WHO I-II }\end{array}$ & $\begin{array}{l}6855(96.0) \\
289(4.0)\end{array}$ & $\begin{array}{l}6668(96.1) \\
270(3.9)\end{array}$ & $\begin{array}{l}187(90.8) \\
19(9.2)\end{array}$ & 0.001 \\
\hline $\begin{array}{l}\text { Diabetes } \\
\text { No } \\
\text { Yes }\end{array}$ & $\begin{array}{l}6960(97.4) \\
184(2.6)\end{array}$ & $\begin{array}{l}6767(97.5) \\
|7|(2.5)\end{array}$ & $\begin{array}{l}193(93.7) \\
13(6.3)\end{array}$ & 0.002 \\
\hline $\begin{array}{l}\text { Smoking history } \\
\text { No } \\
\text { Yes }\end{array}$ & $\begin{array}{l}4359(61.0) \\
2785(39.0)\end{array}$ & $\begin{array}{l}4225(60.9) \\
2713(39.1)\end{array}$ & $\begin{array}{l}\text { I34 (65.0) } \\
72(35.0)\end{array}$ & 0.246 \\
\hline $\begin{array}{l}\text { NPC family history } \\
\text { No } \\
\text { Yes }\end{array}$ & $\begin{array}{l}6330(88.6) \\
814(11.4)\end{array}$ & $\begin{array}{l}6155(88.7) \\
783(11.3)\end{array}$ & $\begin{array}{l}175(85.0) \\
3 \mid(15.0)\end{array}$ & 0.095 \\
\hline $\begin{array}{l}\text { T stage } \\
\text { TI-2 } \\
\text { T3-4 }\end{array}$ & $\begin{array}{l}2119(29.7) \\
5025(70.3)\end{array}$ & $\begin{array}{l}2077(29.9) \\
486 I(70.1)\end{array}$ & $\begin{array}{l}42(20.4) \\
164(79.6)\end{array}$ & 0.003 \\
\hline $\begin{array}{l}\text { N stage } \\
\text { N0-I } \\
\text { N2-3 }\end{array}$ & $\begin{array}{l}3915(54.8) \\
3229(45.2)\end{array}$ & $\begin{array}{l}3819(55.0) \\
3119(45.0)\end{array}$ & $\begin{array}{l}96(46.6) \\
110(53.4)\end{array}$ & 0.019 \\
\hline $\begin{array}{l}\text { Treatment method } \\
\text { RT alone } \\
\text { CCRT } \\
\text { IC+CCRT } \\
\text { Others }\end{array}$ & $\begin{array}{l}\mid 274(\mid 7.8) \\
2568(35.9) \\
|79|(25.1) \\
|5| \mid(2 \mid .1)\end{array}$ & $\begin{array}{l}\mid 236(\mid 7.8) \\
2493(35.9) \\
|73|(24.2) \\
\mid 478(2 \mid .3)\end{array}$ & $\begin{array}{l}38(18.4) \\
75(36.4) \\
60(25.1) \\
33(21.2)\end{array}$ & 0.252 \\
\hline $\begin{array}{l}\text { Radiotherapy method method } \\
\text { IMRT } \\
\text { 2DRT }\end{array}$ & $\begin{array}{l}4012(56.2) \\
3132(43.8)\end{array}$ & $\begin{array}{l}3879(55.9) \\
3059(44.1)\end{array}$ & $\begin{array}{l}133(64.6) \\
73(35.4)\end{array}$ & 0.015 \\
\hline
\end{tabular}

(Continued) 
Table I (Continued).

\begin{tabular}{|c|c|c|c|c|}
\hline \multirow[t]{2}{*}{ Characteristic } & \multicolumn{4}{|l|}{ Number of patients (\%) } \\
\hline & Total cohort $(n=7 \mid 44)$ & Control cohort $(n=6938)$ & Necrotic cohort $(n=206)$ & $p$ \\
\hline Re-radiotherapy & & & & $<0.001$ \\
\hline No & $6898(96.6)$ & $6749(97.3)$ & 149 (72.3) & \\
\hline Yes & $246(3.4)$ & $189(2.7)$ & $57(27.7)$ & \\
\hline Radiotherapy dose (Gy) & & & & 0.474 \\
\hline$\leq 70$ & $5763(80.7)$ & $560 I(80.7)$ & $162(78.6)$ & \\
\hline$>70$ & $138 \mid(19.3)$ & $1337(19.3)$ & $44(21.4)$ & \\
\hline LDH (U/L) & & & & 0.482 \\
\hline$<245$ & $666 \mathrm{I}(93.2)$ & $6466(93.2)$ & $195(94.7)$ & \\
\hline$\geq 245$ & $483(6.8)$ & $472(6.8)$ & II (5.3) & \\
\hline CRP (mg/L) & & & & $<0.001$ \\
\hline$<1$ & $2745(38.4)$ & $2696(38.9)$ & $49(23.8)$ & \\
\hline $\mathrm{I}-3$ & $2276(31.9)$ & $2203(31.8)$ & $73(35.4)$ & \\
\hline$\geq 3$ & $2123(29.7)$ & $2039(29.4)$ & $84(40.8)$ & \\
\hline HGB (g/L) & & & & $<0.001$ \\
\hline$<110$ & $173(2.4)$ & $155(2.2)$ & $18(8.7)$ & \\
\hline $110-150$ & $456 \mid(63.8)$ & $44 I I(63.6)$ & $150(72.8)$ & \\
\hline$\geq 150$ & $2410(33.7)$ & $2372(34.2)$ & $38(18.4)$ & \\
\hline ALB (g/L) & & & & $<0.001$ \\
\hline$<35$ & $26(0.4)$ & $20(0.3)$ & $6(2.9)$ & \\
\hline$\geq 35$ & 7118 (99.6) & 6918 (99.7) & $200(97.1)$ & \\
\hline
\end{tabular}

Notes: All statistical tests were two-sided. $p$-value was calculated with the Pearson $\chi^{2}$ test.

Abbreviations: BMI, body mass index; EBV DNA, Epstein-Barr virus DNA; NPC, nasopharyngeal carcinoma; RT, radiotherapy; CCRT, concurrent chemoradiotherapy; IC, induction chemotherapy; IMRT, intensity-modulated radiotherapy; 2DRT, two-dimensional radiotherapy; LDH, serum lactate dehydrogenase; CRP, C-reactive protein; HGB, hemoglobin; ALB, albumin.

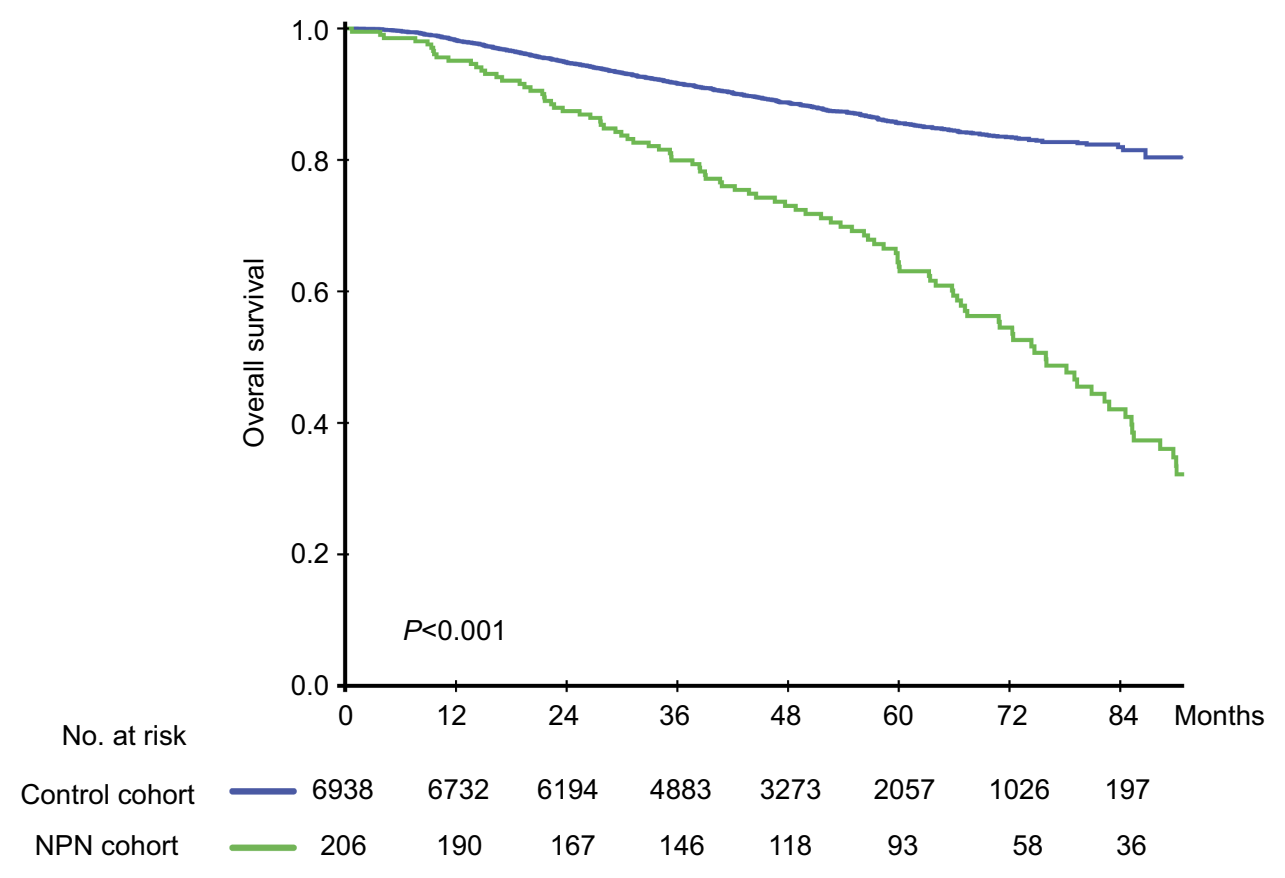

Figure I Kaplan-Meier curves for overall survival in the control cohort and the NPN cohort. Abbreviation: NPN, nasopharyngeal necrosis. 
Table 2 Univariable analysis and multivariable analysis in the cohort

\begin{tabular}{|c|c|c|c|c|}
\hline \multirow[t]{2}{*}{ Characteristic } & \multirow{2}{*}{$\begin{array}{l}\text { Univariable analyses } \\
\text { HR }(95 \% \mathrm{Cl})\end{array}$} & \multirow[t]{2}{*}{$p$} & \multirow{2}{*}{$\begin{array}{l}\text { Multivariable analyses } \\
\text { HR }(95 \% \mathrm{CI})\end{array}$} & \multirow[t]{2}{*}{$p$} \\
\hline & & & & \\
\hline \multicolumn{5}{|l|}{ Age (years) } \\
\hline $18-46$ & Reference & & Reference & \\
\hline$\geq 46$ & $1.46(1.10-1.94)$ & 0.008 & $1.38(1.02-1.87)$ & 0.035 \\
\hline \multicolumn{5}{|l|}{ Gender } \\
\hline Female & Reference & & & \\
\hline Male & $1.35(0.96-1.90)$ & 0.084 & & \\
\hline \multicolumn{5}{|l|}{ BMI } \\
\hline$<18.5$ & Reference & & & \\
\hline $18.5-22.99$ & $1.16(0.68-1.98)$ & 0.596 & & \\
\hline $23-28$ & $1.09(0.63-1.87)$ & 0.766 & & \\
\hline$\geq 28$ & $0.73(0.3|-| .72)$ & 0.469 & & \\
\hline \multicolumn{5}{|l|}{ EBV DNA level } \\
\hline$<1000$ & Reference & & & \\
\hline 1000-9999 & $1.09(0.77-1.55)$ & 0.627 & & \\
\hline 10,000-99,999 & $1.33(0.93-1.89)$ & 0.120 & & \\
\hline$\geq 100,000$ & $0.70(0.42-1.17)$ & 0.174 & & \\
\hline \multicolumn{5}{|l|}{ Pathology type } \\
\hline WHO III & Reference & & Reference & \\
\hline WHO I-II & $2.51(1.54-4.09)$ & $<0.001$ & $2.21(1.30-3.76)$ & 0.003 \\
\hline \multicolumn{5}{|l|}{ Diabetes } \\
\hline No & Reference & & Reference & \\
\hline Yes & 2.67 (1.49-4.77) & 0.001 & $2.39(1.28-4.45)$ & 0.006 \\
\hline \multicolumn{5}{|l|}{ Smoking history } \\
\hline No & Reference & & & \\
\hline Yes & $0.84(0.63-1.12)$ & 0.229 & & \\
\hline \multicolumn{5}{|l|}{ NPC family history } \\
\hline No & Reference & & & \\
\hline Yes & $1.39(0.94-2.06)$ & 0.095 & & \\
\hline \multicolumn{5}{|l|}{ T stage } \\
\hline TI-2 & Reference & & Reference & \\
\hline T3-4 & $1.67(1.18-2.35)$ & 0.003 & $1.46(1.02-2.09)$ & 0.040 \\
\hline \multicolumn{5}{|l|}{ N stage } \\
\hline No-I & Reference & & Reference & \\
\hline N2-3 & $1.39(1.05-1.84)$ & 0.020 & $1.21(0.90-1.63)$ & 0.207 \\
\hline \multicolumn{5}{|l|}{ Treatment method } \\
\hline RT alone & Reference & & & \\
\hline CCRT & $0.98(0.66-1.45)$ & 0.914 & & \\
\hline IC+CCRT & $1.13(0.75-1.70)$ & 0.569 & & \\
\hline Others & $0.73(0.45-1.17)$ & 0.184 & & \\
\hline \multicolumn{5}{|l|}{ Radiotherapy method } \\
\hline IMRT & Reference & & Reference & \\
\hline 2DRT & $0.70(0.52-0.93)$ & 0.014 & $0.54(0.39-0.74)$ & $<0.001$ \\
\hline
\end{tabular}

(Continued) 
Table 2 (Continued).

\begin{tabular}{|c|c|c|c|c|}
\hline \multirow[t]{2}{*}{ Characteristic } & \multirow{2}{*}{$\begin{array}{l}\text { Univariable analyses } \\
\text { HR }(95 \% \mathrm{Cl})\end{array}$} & \multirow[t]{2}{*}{$p$} & \multirow{2}{*}{$\begin{array}{l}\text { Multivariable analyses } \\
\text { HR }(95 \% \mathrm{CI})\end{array}$} & \multirow[t]{2}{*}{$p$} \\
\hline & & & & \\
\hline \multicolumn{5}{|l|}{ Re-radiotherapy } \\
\hline No & Reference & & Reference & \\
\hline Yes & $13.60(9.75-19.15)$ & $<0.001$ & $15.56(10.84-22.35)$ & $<0.001$ \\
\hline \multicolumn{5}{|c|}{ Radiotherapy dose (Gy) } \\
\hline$\leq 70$ & Reference & & & \\
\hline$>70$ & $1.14(0.8 \mathrm{I}-1.60)$ & 0.455 & & \\
\hline \multicolumn{5}{|l|}{ LDH (U/L) } \\
\hline$<245$ & Reference & & & \\
\hline$\geq 245$ & $0.77(0.42-1.43)$ & $0.41 \mathrm{I}$ & & \\
\hline \multicolumn{5}{|l|}{ CRP (mg/L) } \\
\hline$<1$ & Reference & & Reference & \\
\hline $\mathrm{I}-3$ & $1.82(1.26-2.63)$ & 0.001 & $1.87(1.27-2.75)$ & 0.001 \\
\hline$\geq 3$ & $2.27(1.59-3.24)$ & $<0.001$ & $1.99(1.36-2.91)$ & $<0.001$ \\
\hline \multicolumn{5}{|l|}{ HGB (g/L) } \\
\hline$<110$ & Reference & & Reference & \\
\hline $110-150$ & $0.29(0.18-0.49)$ & $<0.001$ & $0.29(0.16-0.52)$ & $<0.001$ \\
\hline$\geq 150$ & $0.14(0.08-0.25)$ & $<0.001$ & $0.14(0.07-0.26)$ & $<0.001$ \\
\hline \multicolumn{5}{|l|}{ ALB $(g / L)$} \\
\hline$<35$ & Reference & & Reference & \\
\hline$\geq 35$ & $0.10(0.04-0.24)$ & $<0.001$ & $0.26(0.09-0.78)$ & 0.016 \\
\hline
\end{tabular}

Notes: Hazard ratios estimated by Cox proportional hazards regression. All statistical tests were two-sided.

Abbreviations: BMI, body mass index; EBV DNA, Epstein-Barr virus DNA; NPC, nasopharyngeal carcinoma; RT, radiotherapy; CCRT, concurrent chemoradiotherapy; IC, induction chemotherapy; IMRT, intensity-modulated radiotherapy; 2DRT, two-dimensional radiotherapy; LDH, serum lactate dehydrogenase; CRP, C-reactive protein; HGB, hemoglobin; ALB, albumin.

( $p=0.63)$. In Figure 4, the $y$-axis denotes the observed NPN probability while the $x$-axis presents the predicted probability derived from the nomogram. The calibration plot also showed satisfactory agreement between the values of prediction and observation in the cohort.

\section{Discussion}

NPN is a severe and devastating adverse event associated with radiotherapy of NPC. ${ }^{3-5}$ NPN occurs unexpectedly and occultly deep in the nasopharynx cavity, but gradually develops as foul odor and severe headache, and sometimes leads to intracranial infection and lethal hemorrhage in severe cases. ${ }^{3,44}$ Because of the rarity of this event, information about the incidence and treatment of NPN is quite limited. This was the first large-scale cohort study that provided a detailed profile of NPN patients and established a nomogram to predict the occurrence of NPN based on the clinical and laboratory indicators of NPC patients. The nomogram demonstrated good discriminative capacity and satisfactory agreement between the predicted and actual results, which should offer valuable clues for clinicians to distinguish the high-risk NPN population and maintain close surveillance for early detection.

Early NPN often appears as mucosal ulceration or a discontinuous mucosa line in MRI, but as the ulceration gradually evolves it erodes the surface of the carotid artery with numerous pathogens reproduced, which would lead to fatal osteoradionecrosis and carotid artery exposure. The NPN-related death rate was $53.0 \%$ in our report, and ranged from $40.2 \%$ to $60.3 \%$ in other studies. ${ }^{3,5,9}$ Worse, the death rates in patients experiencing osteoradionecrosis and carotid artery exposure were as high as $65.8 \%$ and $72.7 \%{ }^{3}$ In Yang et al's study, ${ }^{5}$ re-irradiation and carotid artery exposure were strongly and independently associated with the OS for NPN patients. Re-irradiation, which represented receiving a much higher accumulated radiation dose, could lead to hypoxia, hypovascularity, and hypocellularity 


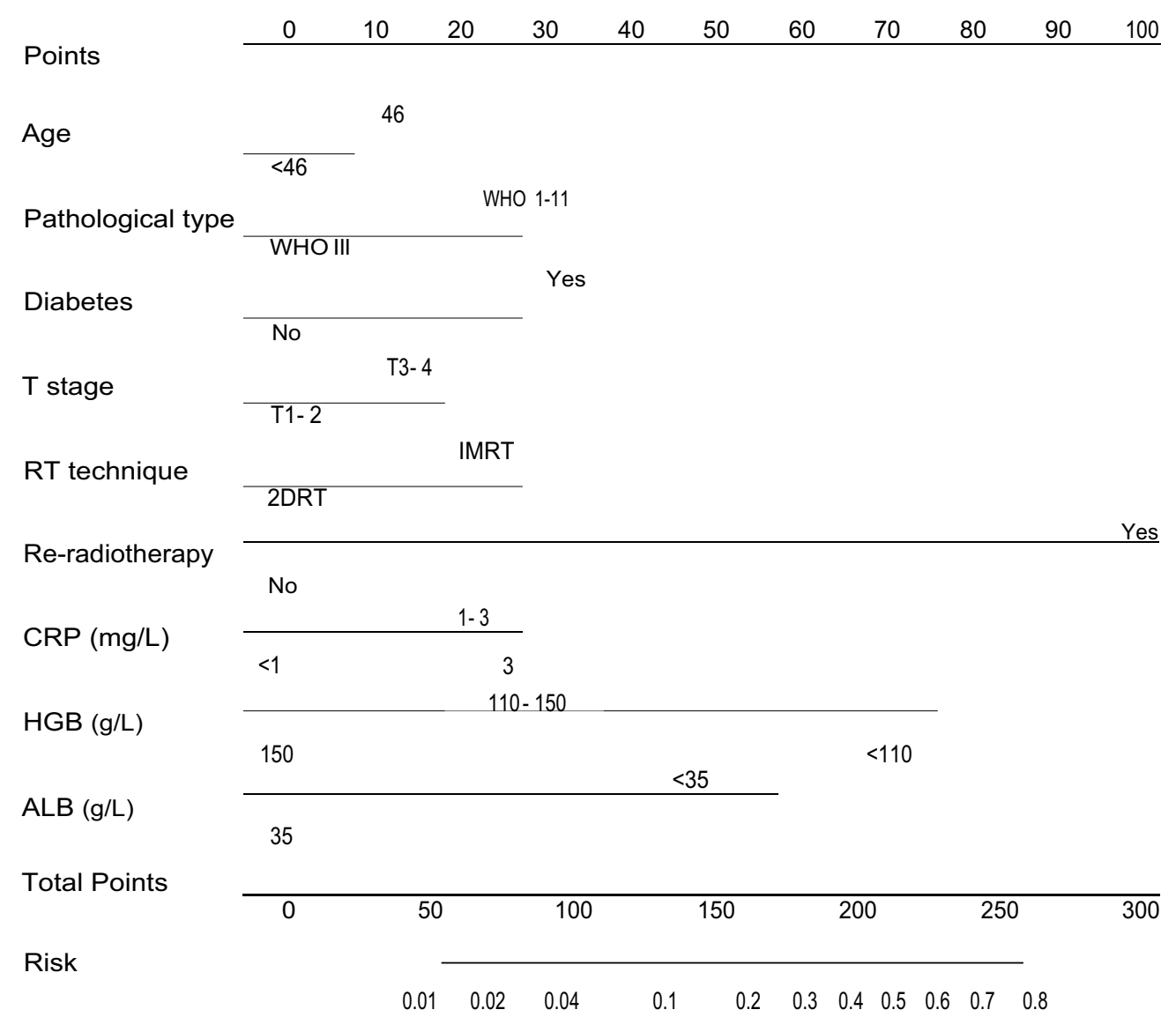

Figure 2 Nomogram including age, pathological type, diabetes, T stage, RT technique, re-radiotherapy, CRP levels, HGB levels, and ALB levels for the development of NPN in patients with nasopharyngeal carcinoma. The nomogram allows clinicians to obtain the probability of developing NPN corresponding to a patient's combination of covariates. Abbreviations: NPN, nasopharyngeal necrosis; IMRT, intensity-modulated radiotherapy; RT, radiotherapy; CRP, C-reactive protein; HGB, hemoglobin; ALB, albumin.

in recurrent NPC patients. As a result, the normal tissue of the nasopharynx was injured and oxygen demand was increasing, which was considered a major risk factor for the development of necrosis. ${ }^{12}$ According to previous studies, the high rate of NPN following re-irradiation has been described with an incidence from $19.9 \%$ to $40.6 \%,{ }^{13-16}$ and accounted for $18.2-35.9 \%$ of deaths in the locally recurrent population, ${ }^{13,15,16}$ which far exceeded the deaths caused by tumor progression. Similar to these results, the experience of re-irradiation contributed most to the occurrence of NPN in our nomogram model. In Liu et al's report, ${ }^{16}$ recurrent patients who received re-irradiation exhibited comparable OS rates with those under only chemotherapy $(27.5 \%$ vs $23.4 \%$ ), and radiation toxicity was the only significant factor correlated with poorer OS. To balance the pros and cons as well as reduce the risk of NPN and NPN-related deaths, a cautious decision should be made to select the proper candidates for re-irradiation.

HGB was an important indicator for patients' nutritional and performance status, the level of which reflected the reduction of blood oxygen and the state of hypoxia in tumor tissues. Previous studies demonstrated that a low level of HGB was closely related to the decreased ability of the blood to carry oxygen. ${ }^{17}$ Additionally, the association between anemia and poor tumor oxygenation has been verified in head and neck cancers. ${ }^{18}$ In terms of survival conditions, multiple studies have revealed that the levels of HGB decrease were independently correlated with poorer survival outcomes in NPC patients. ${ }^{19-22}$ Hypoxia not only reduced tumor radiosensitivity but also delayed the healing of nasopharynx mucosa and created the condition for anaerobics proliferation. ${ }^{23}$ In this study, we found that the pretreatment HGB concentration was also associated with the incidence of tissue necrosis. Thus, anemia may be another reason for the poor prognosis of NPN. However, whether correction of the HGB level could change this situation was still uncertain. The intervention of hyperbaric oxygen was empirically introduced to patients once NPN was detected. In our unpublished data, 75 patients received at least 2 cycles of hyperbaric 


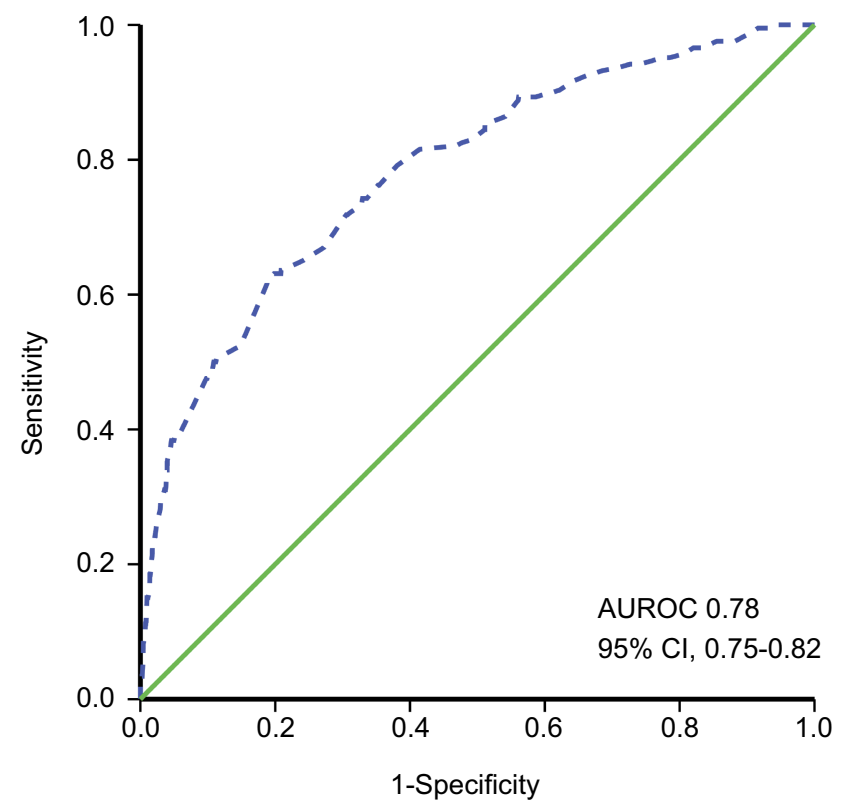

Figure 3 The sensitivity and specificity for the prediction of post-radiation nasopharyngeal necrosis using the nomogram model.

Abbreviation: AUROC, area under the receiver operating characteristic curve.

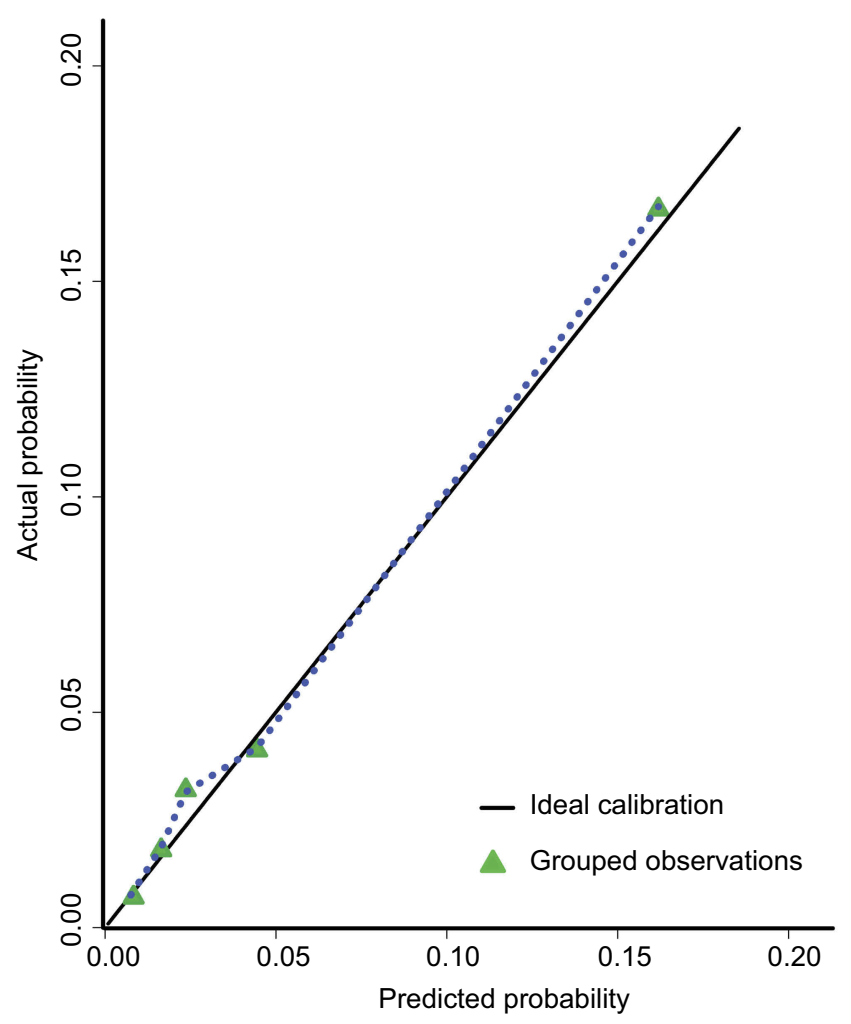

Figure 4 Model calibration curve shows the predicted and actual probability of developing post-radiation nasopharyngeal necrosis.

oxygen; 69 patients (92\%) improved to mild degrees, but the true efficacy of hyperbaric oxygen was vague and warrants further study.
ALB is the most frequently measured index to value the nutritional status as well as reflect an inflammatory condition in cancer patients. CRP is an acute-phase protein serving as a biomarker of inflammation, and has been associated with radiotherapy-induced mucositis in head and neck cancer and breast cancer. ${ }^{24,25}$ Necrosis is the outcome of a highly proinflammatory status. Meanwhile, certain molecules which are thought to promote inflammation could be also released from necrotic cells. ${ }^{26}$ Therefore, a vicious circle is formed. The link between CRP, ALB levels, and the prognosis of cancer was also observed by many reports. ${ }^{27-30}$ Despite whether the tumor or tissue is the source of pretreatment CRP being unclear, the preexisting inflammatory state served as a hallmark in many solid malignancies for tumor development and impaired general condition.

As mentioned above, the development of NPN was a multistep process initiated from irradiation-caused damage to the nasopharynx mucosa, leading to an increase in oxygen demand. Hypovascularity and the low level of HGB aggravated tumor ischemia, and inflammatory cells and cytokines accumulated and interacted resulting in persistent perilesional edema. Once the necrotic lesion formed, treatment strategies including the use of antibiotics, hyperbaric oxygen, nasopharyngeal irrigation, and systemic nutritional support were just feeble attempts. Radical endoscopic necrectomy with nasal flap reconstruction ENNF was recommended by Yang et al's report, ${ }^{5}$ in which 44 endoscopic necrectomy with nasal flap reconstructions were performed and 36 succeeded. However, emphasis should be primarily placed on preventing NPN from happening. Our nomogram model was thus established with pretreatment indexes involved, in a wish to help clinicians to predict the possibility of NPN for each individual. High-risk patients should be closely monitored during and after treatment, and active interventions should be provided including rectifying anemia, tight glucose control, nutritional support, etc.

This study has several limitations. NPN was a smallprobability event, so it was difficult to give detailed information and analyze the treatment effect of these patients given the long time span. The changes of HGB, ALB, and CRP levels during treatment were not considered in this nomogram to avoid being more complicated. External validation of this nomogram model is necessary.

\section{Acknowledgments}

This work was supported by grants from the National Key R\&D Program of China (2017YFC1309003, 
2017YFC0908500), the National Natural Science Foundation of China (No. 81425018, No. 81672868, No. 81602371), the Sci-Tech Project Foundation of Guangzhou City (201707020039), the Sun Yat-sen University Clinical Research 5010 Program, the Special Support Plan of Guangdong Province (No. 2014TX01R145), Natural Science Foundation of Guangdong Province (No. 2017A030312003, No. 2018A0303131004), the Sci-Tech Project Foundation of Guangdong Province (No. 2014A020212103), the Health \& Medical Collaborative Innovation Project of Guangzhou City (No. 201400000001), the National Science \& Technology Pillar Program during the Twelfth Five-year Plan Period (No. 2014BAI09B10), the PhD Start-up Fund of Natural Science Foundation of Guangdong Province, China (2016A030310221), the cultivation foundation for the junior teachers in Sun Yat-sen University (16ykpy28), and the Fundamental Research Funds for the Central Universities.

\section{Disclosure}

The authors report no conflicts of interest in this work.

\section{References}

1. Wee JT, Ha TC, Loong SL, Qian CN. Is nasopharyngeal cancer really a "cantonese cancer"? Chin J Cancer. 2010;29(5):517-526.

2. Lengyel E, Baricza K, Somogyi A, et al. Reirradiation of locally recurrent nasopharyngeal carcinoma. Strahlentherapie Und Onkologie. 2003;179(5):298-305. doi:10.1007/s00066-003-1048-6

3. Chen MY, Mai HQ, Sun R, et al. Clinical findings and imaging features of 67 nasopharyngeal carcinoma patients with postradiation nasopharyngeal necrosis. Chin J Cancer. 2013;32(10):533-538. doi:10.5732/cjc.012.10252

4. Hua YJ, Chen MY, Qian CN, et al. Postradiation nasopharyngeal necrosis in the patients with nasopharyngeal carcinoma. Head Neck. 2009;31(6):807-812. doi:10.1002/hed.21036

5. Yang Q, Zou X, You R, et al. Proposal for a new risk classification system for nasopharyngeal carcinoma patients with post-radiation nasopharyngeal necrosis. Oral Oncol. 2017;67:83-88. doi:10.1016/j. oraloncology.2017.02.012

6. Huang XM, Zheng YQ, Zhang XM, et al. Diagnosis and management of skull base osteoradionecrosis after radiotherapy for nasopharyngeal carcinoma. Laryngoscope. 2006;116(9):1626-1631. doi:10.1097/01. mlg.0000230435.71328.b9

7. Bedwinek JM, Shukovsky LJ, Fletcher GH, Daley TE. Osteonecrosis in patients treated with definitive radiotherapy for squamous cell carcinomas of the oral cavity and naso-and oropharynx. Radiology. 1976;119(3):665-667. doi:10.1148/119.3.665

8. Lam JW, Chan JY, Lui WM, Ho WK, Lee R, Tsang RK. Management of pseudoaneurysms of the internal carotid artery in postirradiated nasopharyngeal carcinoma patients. Laryngoscope. 2014;124 (10):2292-2296. doi:10.1002/lary.24721

9. Yu YH, Xia WX, Shi JL, et al. A model to predict the risk of lethal nasopharyngeal necrosis after re-irradiation with intensity-modulated radiotherapy in nasopharyngeal carcinoma patients. Chin J Cancer. 2016;35(1):59. doi:10.1186/s40880-016-0124-0
10. Edge S, Compton C. The American joint committee on cancer: the 7th edition of the AJCC cancer staging manual and the future of TNM. Ann Surg Oncol. 2010;17(6):1471-1474. doi:10.1245/s10434010-0985-4

11. Pocock S, Clayton T, Altman D. Survival plots of time-to-event outcomes in clinical trials: good practice and pitfalls. Lancet (London, England). 2002;359(9318):1686-1689. doi:10.1016/ S0140-6736(02)08594-X

12. Marx RE. Osteoradionecrosis: a new concept of its pathophysiology. J Oral Maxillofacial Surg. 1983;41(5):283-288.

13. Tian YM, Guan Y, Xiao WW, et al. Long-term survival and late complications in intensity-modulated radiotherapy of locally recurrent T1 to T2 nasopharyngeal carcinoma. Head Neck. 2016;38 (2):225-231. doi:10.1002/hed.23880

14. Hua YJ, Han F, Lu LX, et al. Long-term treatment outcome of recurrent nasopharyngeal carcinoma treated with salvage intensity modulated radiotherapy. Eur J Cancer. 2012;48(18):3422-3428. doi:10.1016/j.ejca.2012.06.016

15. Han F, Zhao C, Huang SM, et al. Long-term outcomes and prognostic factors of re-irradiation for locally recurrent nasopharyngeal carcinoma using intensity-modulated radiotherapy. Clin Oncol ( $R$ Coll Radiol). 2012;24(8):569-576. doi:10.1016/j.clon.2011.11.010

16. Liu LT, Chen QY, Tang LQ, et al. With or without reirradiation in advanced local recurrent nasopharyngeal carcinoma: a case-control study. BMC Cancer. 2016;16(1):774. doi:10.1186/s12885-016-2803-2

17. Rades D, Lang S, Schild SE, Alberti W. Prognostic value of haemoglobin levels during concurrent radio-chemotherapy in the treatment of oesophageal cancer. Clin Oncol ( $R$ Coll Radiol). 2006;18 (2):139-144.

18. Becker A, Stadler P, Lavey RS, et al. Severe anemia is associated with poor tumor oxygenation in head and neck squamous cell carcinomas. Int $J$ Radiat Oncol Biol Phys. 2000;46 (2):459-466.

19. Gao J, Hu JY, Xia YF, Yi W, Tao YL, Li G. Continuous fall in hemoglobin level is a poor prognostic factor in patients with nasopharyngeal carcinoma treated with radiotherapy. Chin $J$ Cancer. 2010;29(5):561-566.

20. Zhang LN, Tang J, Lan XW, OuYang PY, Xie FY. Pretreatment anemia and survival in nasopharyngeal carcinoma. Tumour Biol. 2016;37(2):2225-2231. doi:10.1007/s13277-015-4042-6

21. Gao J, Tao YL, Li G, Yi W, Xia YF. Involvement of difference in decrease of hemoglobin level in poor prognosis of stage I and II nasopharyngeal carcinoma: implication in outcome of radiotherapy. Int J Radiat Oncol Biol Phys. 2012;82(4):1471-1478. doi:10.1016/j. ijrobp.2011.05.009

22. Chua DT, Sham JS, Choy DT. Prognostic impact of hemoglobin levels on treatment outcome in patients with nasopharyngeal carcinoma treated with sequential chemoradiotherapy or radiotherapy alone. Cancer. 2004;101(2):307-316. doi:10.1002/cncr.20366

23. Guo SS, Tang LQ, Chen QY, et al. Is hemoglobin level in patients with nasopharyngeal carcinoma still a significant prognostic factor in the era of intensity-modulated radiotherapy technology? PLoS One. 2015;10(8):e0136033. doi:10.1371/journal.pone. 0136033

24. Hu JJ, Urbanic JJ, Case LD, et al. Association between inflammatory biomarker C-reactive protein and radiotherapy-induced early adverse skin reactions in a multiracial/ethnic breast cancer population. J Clin Oncol. 2018;36(24):2473-2482. doi:10.1200/ JCO.2017.77.1790

25. Mohammed FF, Poon I, Zhang L, et al. Acute-phase response reactants as objective biomarkers of radiation-induced mucositis in head and neck cancer. Head Neck. 2012;34(7):985-993. doi:10.1002/hed. v34.7

26. Davidovich P, Kearney CJ, Martin SJ. Inflammatory outcomes of apoptosis, necrosis and necroptosis. Biol Chem. 2014;395 (10):1163-1171. doi:10.1515/hsz-2014-0164 
27. Sun $\mathrm{P}, \mathrm{Chen} \mathrm{C}, \mathrm{Xia} \mathrm{Y}$, et al. The ratio of C-reactive protein/albumin is a novel inflammatory predictor of overall survival in cisplatin-based treated patients with metastatic nasopharyngeal carcinoma. Dis Markers. 2017;2017:6570808. doi:10.1155/2017/6570808

28. Tao CJ, Chen YY, Jiang F, et al. The C-reactive protein/albumin ratio is an independent prognostic factor for overall survival in patients with nasopharyngeal carcinoma receiving intensity-modulated radiotherapy. $J$ Cancer. 2016;7(14):2005-2011. doi:10.7150/ jca. 16210
29. Fang Y, Xu C, Wu P, et al. Prognostic role of C-reactive protein in patients with nasopharyngeal carcinoma: a meta-analysis and literature review. Medicine. 2017;96(45):e8463. doi:10.1097/MD.0000 000000008463

30. Oei RW, Ye L, Huang J, et al. Prognostic value of nutritional markers in nasopharyngeal carcinoma patients receiving intensity-modulated radiotherapy: a propensity score matching study. Onco Targets Ther. 2018;11:4857-4868. doi:10.2147/OTT.S165133

\section{Publish your work in this journal}

Cancer Management and Research is an international, peer-reviewed open access journal focusing on cancer research and the optimal use of preventative and integrated treatment interventions to achieve improved outcomes, enhanced survival and quality of life for the cancer patient.
The manuscript management system is completely online and includes a very quick and fair peer-review system, which is all easy to use. Visit http://www.dovepress.com/testimonials.php to read real quotes from published authors. 